\title{
Erratum to: Return to work and sports after total hip replacement
}

\author{
J. G. Cowie · G. S. Turnbull • A. M. Ker · S. J. Breusch
}

Published online: 12 February 2014

(C) Springer-Verlag Berlin Heidelberg 2014

Erratum to: Arch Orthop Trauma Surg (2013)

\section{3:695-700}

DOI 10.1007/s00402-013-1700-2

In the original article, one of the co-author's (G. S. Turnbull) family name has been published incorrectly. The correct family name should be Turnbull.

The online version of the original article can be found under doi: 10.1007/s00402-013-1700-2.

J. G. Cowie $(\bowtie) \cdot$ G. S. Turnbull · S. J. Breusch

Royal Infirmary of Edinburgh, 16 Little France Crescent,

Edinburgh EH16 4SU, UK

e-mail: jonathan_cowie@ hotmail.com

A. M. Ker

Glasgow Royal Infirmary, Glasgow, UK 